\title{
Efficacy of Two Rotary Systems Versus Manual Instrumentation During Retreatment: An In Vitro Study
}

\section{Brijila Kuriakose $^{1 *}$ and Rahul Maria ${ }^{2}$}

${ }^{1}$ Post Graduate Student Department of Conservative Dentistry and Endodontics, Bhabha College of Dental Sciences, India

${ }^{2}$ Professor and Head of the Department, Department of Conservative Dentistry and Endodontics, Bhabha College of Dental Sciences, India

*Corresponding Author: Brijila Kuriakose, Post Graduate Student Department of

Conservative Dentistry and Endodontics, Bhabha College of Dental Sciences, India.
Received: February 07, 2022

Published: February 24, 2022

(C) All rights are reserved by Brijila

Kuriakose and Rahul Maria.

\begin{abstract}
Aim: The aim of this study is to evaluate the cleaning efficiency of two rotary retreatment instrumentation techniques and Hand instrumentation technique (H file with solvent) in removing obturating material from the root canal walls, during retreatment procedure using scanning electron microscope.

Material and Methodology: A total of 45 human mandibular Premolar teeth with straight root canals were selected and the coronal one third enlarged with one flare. The biomechananical preparation of the teeth were done till F1 size ProTaper universal rotary file and gutta-percha and AH Plus sealer is used for obturation performed by lateral condensation technique. The samples were divided into three groups according to the retreatment system Group I- H File with solvent, Group II- ProTaper universal retreatment file system and Group III-WaveOne gold primary File. For the evaluation of residual materials, the buccolingually sectioned tooth samples were observed under scanning electron microscope. The statistical analysis of the data was obtained using one way ANOVA and Independent t- test.

Result: The highest amount of remaining filling materials was observed in the apical third followed by middle third and coronal third. WaveOne Gold primary file which works in reciprocating motion showed superior cleaning efficiency than ProTaper universal rotary system which works in continous motion and manual $\mathrm{H}$ file with solvent.

Conclusion: None of the system was able to remove obturating material completely. The efficiency of reciprocating files shown to be superior in removing the filling material compared to continuous retreatment system. The least cleaning efficiency is exhibited by $\mathrm{H}$ file with solvent group in removal of root canal filling material.
\end{abstract}

Keywords: Retreatment; Filling Materials; Gutta-Percha; H File; ProTaper; Rotary System

\section{Abbreviation}

SEM: Scanning Electron Microscope; NiTi: Nickel Titanium

\section{Introduction}

Endodontics is the forerunner in the field of dentistry. The advancement and upgradation in Endodontics commenced time immemorial and still extends. This combines correct investigation of periapical disease and enhancing the outcome of treated teeth [1].
The fundamental in endodontic procedure is complete debridement of infected or necrotic pulp tissue and bacteria and to ultimately seal root canal. Hence, hamper the persistence of infection or re-infection of pulp space. Although root canal treatments have great scale success of $90 \%$, sometimes failures may also accompany [2].

There are multiple reasons of root canal failure which consist of bacterial surveillance as an effect of inadequate cleaning and shap- 
ing, unsatisfactory obturation, over extension of gutta-percha point and improper seal. This drives a hike in application of endodontic retreatment with the removal gutta-percha rather than extraction of affected teeth [3].

In recent past there is surge in endodontic retreatment as a consequence of expanded insistence on conservation of teeth. The range of success of retreatment expected to fluctuate between $50-90 \%$. This variability of outcome in endodontic retreatment is linked to patient's age, tooth form, existence modified sources of root canals, the removing coronal restoration to get entry into pulp chamber repairing iatrogenic and pathologic errors [4].

The predictors for best outcome of endodontic retreatment include preoperative perforations, apical periodontitis and the condition of past filling material. Failure of endodontic treatment is established on the basis clinical signs and symptoms and confirmed by analysing radiographic data of affected teeth $[4,5]$.

The objective of retreatment is to reach apical foramen by ultimate removal of filling material, accordingly, promoting acceptable cleaning and shaping of root canal system and obturation. Thus, recreating normal healthy periodontium [5].

There are various means of gutta-percha removal from the root canals consisting of manual removal by hand instrument, heat carrying instrument, nickel titanium rotary instruments and laser. Traditionally, manual files were used for the removal gutta percha with or without solvent can be time taking and inefficient when the filling is well condensed. Thus, nickel titanium rotary came into application in retreatment and research recorded their effectiveness, quality of cleaning anpd safety during the course of retreatment [6].

Complete removal of filling material is necessary in retreatment as the remaining filling material can act as an inlet of necrotic tissue or micro-organisms which could be the reason for further pain and complication of retreatment. Studies concluded that complete elimination of filling material is impractical.

Hence this study is undertaken to evaluate the percentage of remaining filling material left in coronal, middle, apical portion of root canal walls using hand file with solvent and three different rotary systems.

\section{Materials and Methods}

A 45 permanent mandibular premolar with straight root canal extracted for orthodontic and periodontal reason, confirmed by radiograph were collected for the study. The institutional ethical committee approved the study. The teeth were stored in $1 \%$ sodium hypochlorite to eliminate organic debris. They were then removed, washed under tap water and stored in 10\% Formalin solution for the disinfection of the teeth, till they were used for the purpose of the study.

Coronal Access cavities were prepared using BR 41 round bur and canals were located with the help of a DG 16 probe. The patency was determined by 10 size and15 size K-file, placing inside the canal until its visibility at the apical foramen. Whenever there is resistance with 10 size $\mathrm{K}$ file, Proglider were used. The working length was established with cusp tip as reference point to $0.5 \mathrm{~mm}$ short of anatomic apex. The coronal enlargement was done by one flare rotary file. Then, the canal was instrumented with ProTaper files coated with Glyde chelating paste size S1, S2 and final finishing of apical portion will be done with F1. Irrigation of the canal was done in between the use of each file with $5.25 \%$ sodium hypochlorite. Once complete preparation was done, irrigation of the root canals was obtained with $5.25 \%$ sodium hypochlorite, saline and citric acid $40 \%$ as final irrigant.

Paper points and endo aspirator was used for drying the canal. After inserting gutta-percha cones into canals, it was verified for working length and apical fit which is confirmed by radiograph. The Obturation was done using master gutta percha cone with AH Plus sealer mixed according to the manufacturer's instruction by lateral condensation technique. Hand spreader and accessory cones were also used.

The gutta-percha was sheared off from the pulp chamber with a heated plugger at the level of canal orifice. The sealing of access cavities was accomplished using cotton pellet and temporary filling material (Cavit Espe Dental, Medizin, Germany).

The quality and apical extent of the root canal filling were assessed with radiograph and stored at $37^{\circ} \mathrm{C}$ under $100 \%$ relative humidity for 30 days to provide complete sealer setting. 


\section{Retreatment}

Three groups containing 15 teeth specimens assigned by selecting the tooth in a random manner. Firstly, small ditch was made with peeso-reamer size 1 and the canals were retreated with one of the following methods

- Group I-H files with solvent (Mani, Japan): A $0.4 \mathrm{ml}$ of Eucalyptol solvent carried using insulin syringe and placed in canal to soften gutta-percha. After two minutes, to allow for solvent penetration, the filling material was removed with $\mathrm{H}$-files of sizes 20, 25 and 30 with a quarter turn circumferential pushpull motion till the working length was reached.

- Group II-Protaper universal retreatment files (Dentsply, Maillefer): ProTaper universal retreatment instruments were used at 500-700 rpm and a torque setting of upto $2.5 \mathrm{Ncm}$ to remove root filling by using D1, D2, D3 retreatment instruments. With a brushing movement, ProTaper Universal retreatment files were used against the canal walls using D1 in cervical third, D2 in middle third and D3 in apical third in a crown-down technique until reaching the working length as recommended by the manufacturer for removing sealer and gutta-percha

- Group III- WaveOne gold (Dentsply, Maillefer): A primary reciprocating waveone gold primary file of size 25 and a 0.07 taper was used in a reciprocation mode according to manufacturer's instructions. Slow in-and-out pecking motion were exerted under controlled speed and torque by an average of around $3 \mathrm{~mm}$ each time with limited apical pressure and brushing movements against walls of the canal. After three pecks of working, flutes of the instruments were cleaned.

Complete removal of the material considered when the instrument did not collect any more filling material after insertion and removal in the canal. After the completion of retreatment procedure, all roots were radiographed to inspect the removal of filling material by various techniques of removal. Irrigation using $5 \mathrm{ml}$ of $5.25 \%$ sodium hypochlorite was carried out in between all instrument changes and smear layer was removed by citric acid $40 \%$.

\section{Tooth sectioning and microscopic examination}

At the end, all the canals were washed and dried with absorbent paper points (Dentsply). All samples were decoronated with using a diamond disc to ensure standardization in the study with a root length of $16 \mathrm{~mm}$ in each case. The teeth were grooved in a buccolingual direction and sectioned with chisel longitudinally. The section with more visible part was selected. Till the time of SEM evaluation, specimen were stored in aqueous solution of $2.0 \%$ glutaraldehyde.
The statistical analysis was done using statistical package of social sciences (SPSS) software, v.22, the comparison of mean scores between groups and between different areas of root were calculated by using One way ANOVA and Independent ' $t$ ' test. The difference will be considered as significant, when the P value is below 0.05 .

\section{Results}

Considering the study result, it was observed that the apical third exhibited a greater amount of residual filling material than in middle third and cervical thirds irrespective of the technique used in this study. In our study WaveOne gold file showed superior cleaning efficiency compared to ProTaper Universal Retreatment system and Hand file with solvent.

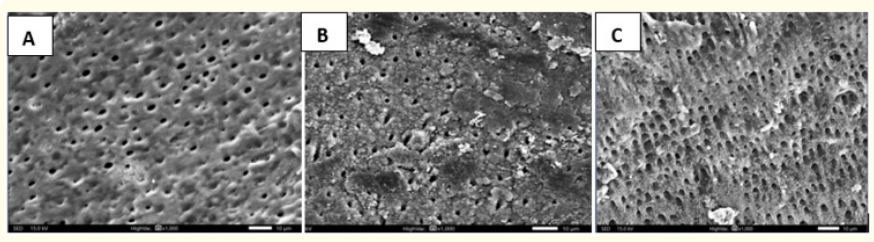

Figure 1: SEM images sowing Group I-H File with solvent A: Coronal third B: Middle third C: Apical third under 1000 magnification.

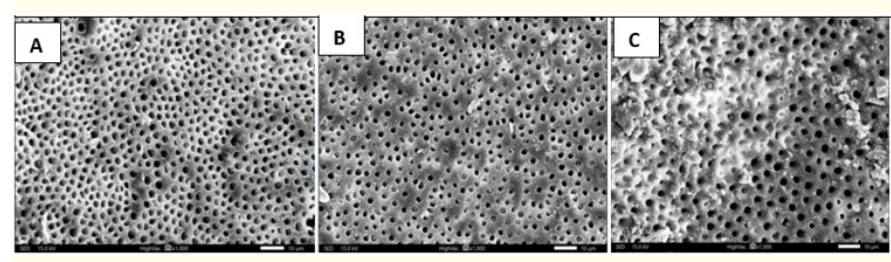

Figure 2: SEM images sowing Group II-Protaper universal retreatment File A: Coronal third B: Middle third C: Apical third under 1000 magnification.

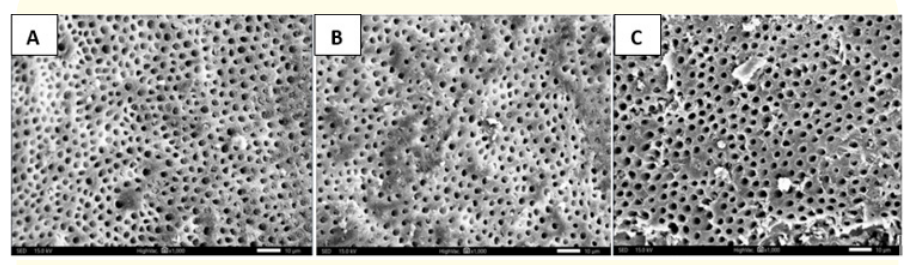

Figure 3: SEM images sowing Group III-Waveone Gold Primary File A: Coronal third B: Middle third C: Apical third under 1000 magnification. 


\begin{tabular}{|c|c|c|c|c|c|}
\hline & Coronal & $\begin{array}{c}\text { Middle_ } \\
\text { third }\end{array}$ & $\begin{array}{c}\text { Apical_ } \\
\text { third }\end{array}$ & F value & P value \\
\cline { 1 - 4 } $\mathrm{N}$ & 15 & 15 & 15 & \multirow{2}{*}{15.451} & $<0.001$ \\
\cline { 1 - 4 } Mean & 1.0000 & 1.2667 & 2.0000 & & \\
\cline { 1 - 4 } Std. Deviation & .75593 & .45774 & .00000 & & \\
\cline { 1 - 4 } Minimum & .00 & 1.00 & 2.00 & & \\
\cline { 1 - 4 } Maximum & 2.00 & 2.00 & 2.00 & & \\
\hline
\end{tabular}

Table 1: Mean scores of filling material removal at different levels using H file with solvent.

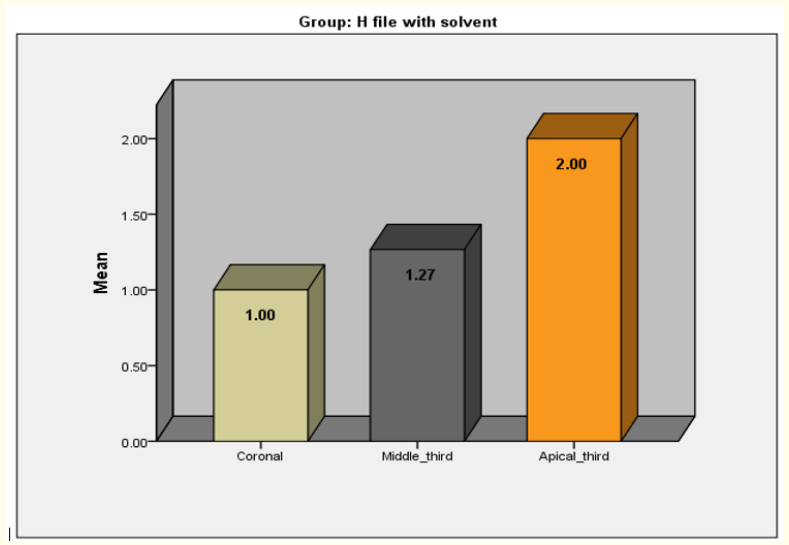

Graph 1: Bargraph showing the means scores of the filling material removal at different levels using $\mathrm{H}$ file with solvent.

\begin{tabular}{|c|c|c|c|c|c|}
\hline & Coronal & $\begin{array}{c}\text { Middle } \\
\text { third }\end{array}$ & $\begin{array}{c}\text { Apical } \\
\text { third }\end{array}$ & F value & P value \\
\cline { 1 - 4 } $\mathrm{N}$ & 15 & 15 & 15 & \multirow{2}{*}{88.90} & $<0.001$ \\
\cline { 1 - 4 } Mean & .0000 & .8000 & 1.7333 & & \\
\cline { 1 - 4 } Std. Deviation & .00000 & .41404 & .45774 & & \\
\cline { 1 - 4 } Minimum & .00 & .00 & 1.00 & & \\
\cline { 1 - 4 } Maximum & .00 & 1.00 & 2.00 & & \\
\hline
\end{tabular}

Table 3: Mean scores of filling material removal at different levels using Wave one.

\begin{tabular}{|c|c|c|c|c|c|}
\hline & Coronal & $\begin{array}{c}\text { Middle } \\
\text { third }\end{array}$ & $\begin{array}{c}\text { Apical } \\
\text { third }\end{array}$ & F value & P value \\
\cline { 1 - 4 } $\mathrm{N}$ & 15 & 15 & 15 & & \\
\hline Mean & .0000 & 1.0000 & 1.8000 & & \\
\cline { 1 - 4 } Std. Deviation & .00000 & .00000 & .41404 & \multirow{2}{*}{213.50} & $<0.001$ \\
\cline { 1 - 4 } Minimum & .00 & 1.00 & 1.00 & & \\
\hline Maximum & .00 & 1.00 & 2.00 & & \\
\hline
\end{tabular}

Table 2: Mean scores of filling material removal at different levels using Protaper.

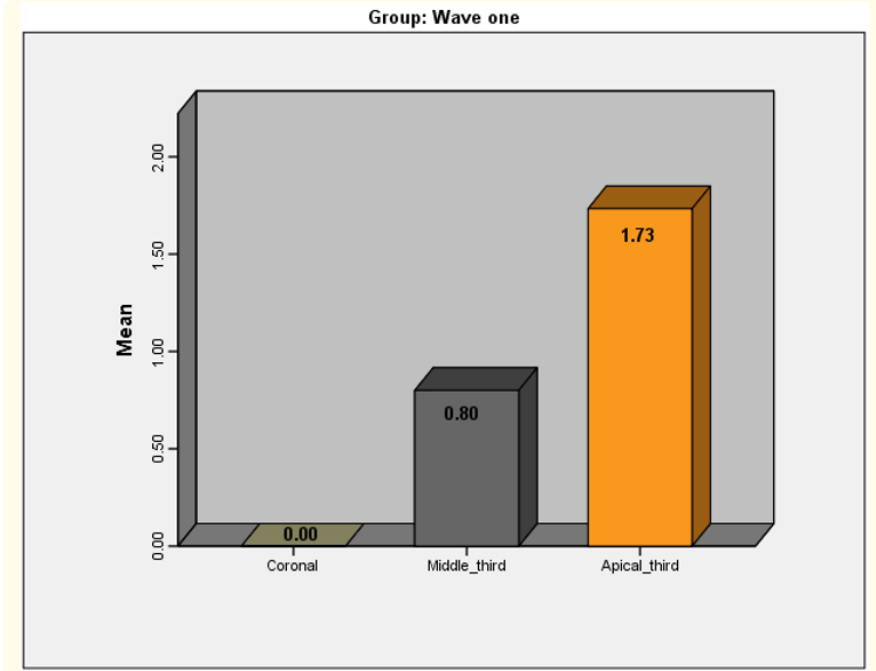

Graph 3: Bar graph showing the mean scores of filling material removal at different levels using Protaper. 


\begin{tabular}{|c|c|c|c|c|c|c|c|c|}
\hline & \multicolumn{6}{|c|}{ Group } & \multirow{3}{*}{ F Value } & \multirow{3}{*}{$P$ value } \\
\hline & \multicolumn{2}{|c|}{ H file with solvent } & \multicolumn{2}{|c|}{ Protaper } & \multicolumn{2}{|c|}{ Wave one } & & \\
\hline & Mean & $\begin{array}{l}\text { Standard } \\
\text { Deviation }\end{array}$ & Mean & $\begin{array}{l}\text { Standard } \\
\text { Deviation }\end{array}$ & Mean & $\begin{array}{l}\text { Standard } \\
\text { Deviation }\end{array}$ & & \\
\hline Coronal & 1.00 & .76 & .00 & .00 & .00 & .00 & 26.250 & $<0.001^{* *}$ \\
\hline $\begin{array}{l}\text { Middle } \\
\text { third }\end{array}$ & 1.27 & .46 & 1.00 & .00 & .80 & .41 & 6.475 & $0.004^{*}$ \\
\hline $\begin{array}{l}\text { Apical } \\
\text { third }\end{array}$ & 2.00 & .00 & 1.80 & .41 & 1.73 & .46 & 2.275 & 0.115 \\
\hline
\end{tabular}

Table 4: Comparison of the mean scores of filling material removal at different levels using various techniques.

*Significant, ** Highly Significant

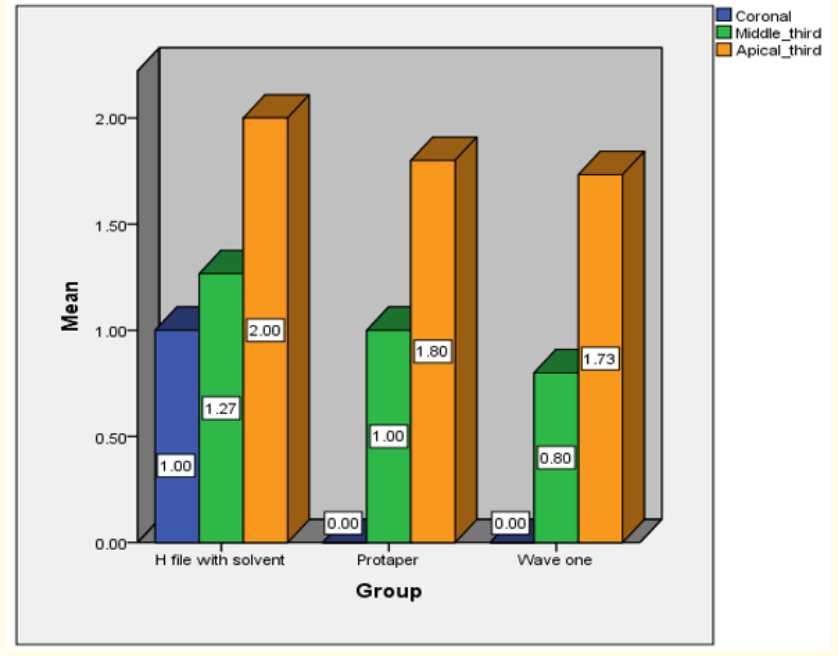

Graph 4: Bargraph showing the comparison of the mean scores of filling material removal at different levels using various techniques.

\section{Discussion}

Root canal therapy despite of having high rate of success, may not lead to normal healthy response. A few numbers of cases could not react to endodontic therapy for a various reason which could cause failure of the treatment [7].

The main reason for unfavourable results following root canal treatment is the survival of bacteria within the intricacies of root canal system. Tenderness to percussion, sensitivity with hot and cold, recurrent abscess, fistula and visible periapical lesion radiographically are the clinical signs and symptoms of Endodontic treatment failure $[7,8]$.
Nonsurgical endodontic retreatment is generally adopted more than Endodontic surgery considering possible complications after the surgery. One of the prime challenges in the current practice system is the Retreatment in endodontic therapy. The complete debridement of root canal filling material gives a predictable outcome in a nonsurgical endodontic retreatment. Thus, compulsory removal of filling material from a failed root canal is essential to eradicate microbes and the remaining necrotic tissue, which may contribute to endodontic failure. This will ensure the free passage of endodontic irrigants and flushing out debris and bacteria existed in the root canal space and dentinal tubules. As the dentinal tubule can be reservoir for bacteria, they should be thoroughly disinfected with irrigant after complete removal of filling material $[7,8]$.

A wide range of instruments are suitable for retreatment which includes Hand instrument with and without solvent, heat carrying instrument, nickel titanium rotary instrument with and without solvent and lasers. These instruments are generally used for retreatment in different combination. Earlier studies showed that apical third of root canal remains challenging during cleaning and shaping with the application by most of the available techniques [4-7].

In our study, retreatment was done using, Group I - H File with solvent, Group II- ProTaper Universal Retreatment system, Group III- WaveOne Gold file was used.

Various techniques have been applied to assess the residual filling material on dentin surface following different removal techniques such as clearing and optical Stereomicroscope, light microscope, radiograph, rendered transparent teeth, CBCT, micro-CT, SEM etc [8]. 
In our study Scanning Electron Microscope (SEM) is used, since it allows acquisition of images of area covered by debris or smear layer and enables the identification of patent dentinal tubules under high resolution. All other possible techniques including microCT has only limited resolution power to discover these features [8].

The scoring of SEM images were carried out blindly by two endodontist using criteria modified by Bernardes., et al. and Pirani., et al. as follows $[9,10]$.

- Score 0: Absence of smear layer and filling debris with more than $75 \%$ of the tubule exposed and opened

- Score 1: Smear layer and filling debris present in limited areas with $75 \%$ of tubule exposed

- Score 2: Smear layer and filling debris often present, $<50 \%$ of tubule visibly exposed in a limited area

- Score 3: Smear layer and filling debris present above all dentin, no tubules visible

It was observed that a greater amount of filling material noticed in the apical third compared to middle third and cervical thirds irrespective of the technique used. This result is corroborates with previous studies reported by Unal., et al. [6].

In our study WaveOne gold file showed superior cleaning efficiency compared to ProTaper Universal Retreatment system and Hand file with solvent. Reciprocating instruments have proven to maintain excellant efficiency to standard rotary files during endodontic retreatment. This superior property could be because of the of the reciprocation motion with the connection towards the balanced force rotation of hand files (back and forth reciprocating rotation) keeping the centering ratio of the file in the path of the canal and reaching the apex in a better way. In addition, greater contact area between the file and root filling were attributed by the reciprocation motion that may improve the removal of the root filling [11,12].

The sufficient space for enhanced cutting, loading and transportation of root canal debris in a coronal direction are all contributed by the parallelogram shaped cross-section of WaveOne gold file. The offset cross-sectional shape and reduced taper of the file which favours penetration and extrusion of the filling material coronally is the reason behind better cleaning efficiency of WaveOne gold. The semi-active tip also aids in recommending its use in endodontic retreatment. The improved shape memory of WaveOne gold could be the factor which favours the prevention of strips and ledges during retreatment procedures. It has improved property because of NiTi gold alloy $[13,14]$.

In Group II, ProTaper Universal Retreatment system works on continuous full rotation with brushing movements against the canal wall in crown down manner which pulls the root filling material towards the orifice, thus removing the obturating material. Large amount of gutta-percha removal with ProTaper Universal retreatment system occurs through spirals running around the instrument, which cuts and soften gutta-percha at the same time [15,16].

The various design feature of the ProTaper including cutting edges, flutes, varied taper and varied length allowed its performance in retreatment. The negative cutting angle and the absence of radial land create an action of cutting as opposed to an action of planning on gutta-percha. Since the diameter of the instruments is small, some form of difficulties was felt in the initial penetration into the filling material. The pressure required to remove the filling material was more in ProTaper instruments when compared to Group III - WaveOne file $[15,17]$.

In our study Group III -H file with solvent had least cleaning efficiency compared to other two groups. This may be due to design of $\mathrm{H}$ file that their positive rake angle cuts only in one motion that is the withdrawal motion. The Hand file could not directed effectively towards the canal wall as it is having higher stiffness than NiTi rotary instrument. The manual instrumentation does not produce frictional heat leaving more amounts of residual filling materials in root canals. One side of $\mathrm{H}$ file is noncutting leading to more accumulation of debris.

The push and pull action of filing by safe sided $\mathrm{H}$ file at as piston possess a challenge in pumping the debris through apical foramen. Moreover, the force acting on to the Hedström files is an operatordependent factor that can vary between each operator leading to a variation in results $[18,12]$.

We have used solvent which could have increased the solubility of sealer within the dentinal tubules, which in turn responsible for partial blockage of the dentinal tubules. More amount of debris in this group might be because of solvent action which softens the root filling material that may be easily compacted into dentinal tubules from which it cannot be easily removed. This result is in agreement with previous study done by Horvath., et al. [19]. 
Our result is also in accordance with Al-Obaidi., et al. (2016) Comparing of the Effectiveness of Reciprocating System with Continuous Rotary Systems in Non-Surgical Endodontic Retreatment. He did comparison among group I: reciprocating technique and WaveOne system, group II: continuous technique and ProTaper retreatment system, group III: continuous technique and R-Endo system, group IV: continuous technique and D-RaCe retreatment system. This study came to the conclusion that all the retreatment systems lead to different results did not effectively removes the filling material in the root canal. The reciprocating technique was most effective method for removing gutta-percha and sealer than continuous rotary technique [20].

The studies done by R N Nawaf 2021, Maiti N., et al. 2014, Guilani V., et al. 2008 concluded that the apical third had the most residual gutta-percha and sealer compared to the coronal and middle third due to the presence of apical curvatures, deltas, ramifications and the lack of control with the currently available instruments. Our study results are also in accordance to the above listed studies $[21,22]$.

Under the condition of the present study, it was impossible to completely remove root canal filling materials irrespective of which technique is used. WaveOne gold instrument were significantly more effective in the removal of obturating material from the walls of the canals in comparison to ProTaper retreatment system and $\mathrm{H}$ files with solvent when used.

\section{Conclusion}

Under the conditions of this in vitro study, the results showed that

- None of the systems tested were able to remove residual gutta-percha and sealer completely from the root canals.

- The reciprocating instrumentation techniques was the most efficient method for removing gutta-percha and sealer, followed by the continuous rotary instrumentation techniques and the manual instrumentation techniques.

- The percentage of remaining filling material in the root canal wall after retreatment was least in WaveOne Gold Primary file followed by ProTaper Universal retreatment file and H File with solvent being the highest.
- $\quad$ The percentage of remaining filling material after retreatment exhibited least in coronal area followed by middle area and apical area.

\section{Conflict of Interest}

The authors deny any conflicts of interest.

\section{Bibliography}

1. PK Thaku Raj., et al. "Evaluation of effectiveness of two different Endodontic Retreatment systems in removal of gutta percha: An invitro study". Journal of Contemporary Dentistry 19.6 (2018): 726-731.

2. Saad AY., et al. "Efficacy of two rotary NiTi instruments in the removal of gutta-percha during root canal retreatment". The Journal of Endodontics 33 (2007) :38-41.

3. Giuliani V., et al. "Efficacy of ProTaper universal retreatment files in removing filling materials during root canal retreatment". The Journal of Endodontics 34.11 (2008) 1381-1384.

4. Farzaneh M., et al. "Treatment outcome in endodontics: the Toronto study-phases I and II: orthograde retreatment". The Journal of Endodontics 30 (2004): 627-633.

5. Stabholz A., et al. "Endodontic retreatment: case selection and technique. Part2: treatment planning for retreatment". The Journal of Endodontics 12 (1988): 607-614.

6. Unal C., et al. "A comparison of the efficacy of conventional and new retreatment instruments to remove gutta-percha in curved root canals: an ex vivo study". International Endodontic Journal 42 (2009): 344-350.

7. Hasija MK., et al. "Evaluation of Gutta-Percha Removal from the Dentinal Tubules Using Different Instrumentation Techniques with or Without Solvent: An In vitro Study". Journal of the International Clinical Dental Research 12 (2020): 27-32.

8. Schwerz L., et al. "Comparison of the effectiveness of the protaper system versus hand instrumentation in endodontic retreatment: a scanning electron microscopy study". RSBO Le Réseau de Recherche en Santé Buccodentaire et Osseuse 9.4 (2012); 368-374. 
9. RA Bernardes., et al. "Comparison of three retreatment techniques with ultrasonic activation in flattened canals using micro-computed tomography and scanning electron microscopy". International Endodontic Journal 49.9 (2016): 890-897.

10. Pirani C., et al. "Effectiveness of Three Different Retreatment Techniques in Canals Filled with Compacted Gutta-Percha or Thermafil: A Scanning Electron Microscope Study". The Journal of Endodontics 35.10 (2009): 1433-1440.

11. Nouri H., et al. "Comparison of full rotation and reciprocating movements in regaining apical patency during endodontic retreatment". Journal of Dental Research 18 (2021): 85.

12. Akbulut MB., et al. "Efficacy of Twisted File Adaptive, Reciproc and ProTaper Universal Retreatment instruments for rootcanal-filling removal: A cone-beam computed tomography study". Dental Materials Journal 35.1 (2016): 126-131.

13. Keskin C., et al. "Efficacy of novel thermomechanically treated reciprocating systems for gutta-percha removal from root canals obturated with warm vertical compaction". Journal of Dental Research, Dental Clinics, Dental Prospects 12.2 (2018): 110-115.

14. Mărușter R., et al. "The Efficacy of Waveone Gold and Mtwo retreatment files in the removal of carrier-based gutta-percha obturators". Journal of Oral Rehabilitation 12.3 (2020): 55-63.

15. Fatima K., et al. "Efficacy of rotary and reciprocating single-file systems on different access outlines for gutta-percha removal in retreatment: An in vitro study". Journal of Conservative Dentistry 21 (2018): 354-358.

16. Meyappan R., et al. "Effectiveness of Conventional and three different Rotary Retreatment techniques in canals obturated with Gutta Percha: A Scanning Electron Microscopic Study". Endodontology 26.2 (2014): 259-265.

17. Fariniuk LF., et al. "Efficacy of Five Rotary Systems versus Manual Instrumentation During Endodontic Retreatment". Brazilian Dental Journal J 22.4 (2011): 294-298.

18. Kasam S., et al. "Efficacy of Different Methods for Removing Root Canal Filling Material in Retreatment - An In-vitro Study". Journal of Clinical and Diagnostic Research 10.6 (2016): ZC06ZC10.
19. SD Horvath., et al. "Cleanliness of dentinal tubules following gutta-percha removal with and without solvents: a scanning electron microscopic study". International Endodontic Journal 42 (2009): 1032-1038.

20. Al-Obaidi MA., et al. "Comparison of the Effectiveness of Reciprocating System with Continuous Rotary Systems in NonSurgical Endodontic Retreatment (An In vitro study)". Journal of Baghdad College of Dentistry 28.1 (2016): 57-62.

21. Nawaf RN., et al. "Retreatment Efficacy of Continuous Rotation Versus Reciprocation Kinematic Movements in Removing Gutta-Percha with Calcium Silicate-Based Sealer: SEM Study". Journal of Research in Medical and Dental Science 9.5 (2021): 80-87.

22. Gu LS and Ling JQ. "Efficacy of ProTaper Universal rotary retreatment system for gutta-percha removal from root canals". International Endodontic Journal 41.4 (2008): 288-295.

23. Silva EJN., et al. "Effectiveness of rotatory and reciprocating movements in root canal filling material removal". Brazilian Oral Research 29.1 (2015): 1-6.

24. Schirrmeister J., et al. "Effectiveness of a hand file and three nickel-titanium rotary instruments for removing gutta-percha in curved root canals during retreatment". Oral Surgery, Oral Medicine, Oral Pathology, and Oral Radiology Endodontic 101 (2006): 542-547.

\section{Assets from publication with us}

- Prompt Acknowledgement after receiving the article

- Thorough Double blinded peer review

- Rapid Publication

- Issue of Publication Certificate

- High visibility of your Published work

Website: www.actascientific.com/

Submit Article: www.actascientific.com/submission.php Email us: editor@actascientific.com Contact us: +919182824667 